\title{
LIS students and plagiarism in the networked environment
}

\author{
Ivana Hebrang Grgić \\ Faculty of Humanities and Social Sciences, University of Zagreb / Department of Information and Communication \\ Sciences, Zagreb, Croatia \\ ihgrgic@ffzg.hr
}

\begin{abstract}
Plagiarism is unethical behaviour that can have negative consequences on the development of science and society. It also ruins the reputation of individuals and institutions. Plagiarism can be intended or unintended. The paper will focus on unintended plagiarism that is a result of absence of that topic in the education curricula. Teaching about plagiarism is part of so-called ethical literacy that is a subcategory of information literacy. A survey was conducted with the aim of finding out about the degree of knowledge about plagiarism among the students of Library and Information Science at the Faculty of Humanities and Social Sciences, University of Zagreb. The analysis is based on an anonymous web questionnaire with 20 questions. The presumption is that the students do not know enough about plagiarism, they have not had any experiences with plagiarism during their education and they do not know what self-plagiarism is. Another presumption is that the students get detailed instructions about how to cite sources, but do not know enough about the concept of authorship. The conclusion will be made about the inclusion of this segment of information literacy in education curricula. New surveys will be proposed (on local and national level).
\end{abstract}

\section{INTRODUCTION}

In the networked environment, students have access to enormous amount of information. That can be a good thing if they understand what research integrity is, so they can act ethically. However, there are many challenges in the electronic environment (easy copy-paste solution being one of them). In this paper, we will not focus on intended unethical practices, but on the unintended ones. Unintended practices in the field of research integrity are based on the lack of education about ethical issues. The aim of this research is to give a short overview of literature about students' understanding of plagiarism and authorship; to present the results of a survey of graduate students of Library and Information Science; and to conclude about their understanding of some ethical issues in academia.

Olson and Show [1] show that children at the age of 5 or 6 are capable of understanding the originality of ideas - they consider characters that copied other characters' words as "bad". Based on the study, Bailey [2] concludes that the best time to start plagiarism education is in the third grade (age 8). The education has to be well planned. Bailey also poses a question about the generation gap - how is it possible that young children understand the value of originality and students lose the understanding (as many studies and practices show)?

\section{LITERATURE OVERVIEW}

McCabe [3] conducted several longitudinal researches about academic dishonesty and cheating among students. A part of one of his researches was about North American undergraduate and graduate college students and their practices in written assignments. 36\% of undergraduate students and $24 \%$ of graduate students have, at least once, copied or paraphrased Internet sources without giving credits to authors (i.e. without citing the sources). At the same time, $58 \%$ of undergraduate and $62 \%$ of graduate students think that such a behaviour is not appropriate. Risquez et al. [4] found out that $75 \%$ of students had high ethical awareness that copying text without citation was wrong. Armstrong and Delbridge [5] found out that $30-55 \%$ of students from the field of Information Science admitted minor plagiarism activity (e.g. copying a small part of another student's paper or inclusion of a quote without intext citation). Major plagiarism activity is reported by 9 $20 \%$ of students (e.g. buying an essay from a writing service or unacknowledged summarizing of a large amount of published work). According to the survey, the first reason why students commit plagiarism is easy access to online material and the second is that they do not know what plagiarism is. They plagiarize mostly because of pressure to complete their assignments and because of poor time management skills

Analysing the reasons for cheating and plagiarism, Dornan et al. [6] conclude that the main reasons are misunderstanding of the assignment and running out of time. Some other reasons could be lack of research skills, problems with evaluating sources, confusions about terminology, confusions between plagiarism and paraphrasing, careless notetaking, confusions about how to cite sources etc. [7]. There are four main forms of plagiarism among students [8]:

1. intra-corpal (students cheat by copying from their colleagues in the same class);

2. collusion (student presents the paper as his own, but in fact it is the result of cooperation with another person who is not stated as a co-author)

3. extra-corpal (students cheat by copying from external source, e. g. book, journal or a web site)

4. self-plagiarism (or auto-plagiarism - students use their own works previously submitted for another assignment without acknowledgment). 
Kokemuller [9] writes how plagiarism affects students. They can fail an assignment, fail a class or even be suspended. Besides destroying student's reputation, there can also be legal and monetary repercussions. Sometimes, if the students are involved in medical researches, plagiarism can cause the loss of human lives [10].

When students' papers are published, authorship should be properly assigned. There are four main authorship criteria according to ICMJE: substantial contributions to the conception or design of the work; drafting the work or revising it critically; giving final approval of the version to be published; agreement to be accountable for all aspects of the work [11]. American Psychological Association (APA) published guidelines on determining authorship credit and authorship order for students [12]. The guidelines are based on the APA code of ethics. The most important is an open discussion on authorship issues among all the students and/or researchers involved in a project. In addition, student should be listed as principal author on an article based on the students' thesis. It is possible to use authorship agreements to outline the types of contributions (responsibilities, roles, efforts etc.). Wager [13] thinks that listing contributions can make easier for editors to detect ghost authors. Ghost authors are those authors who made substantial contributions to the paper (they meet all the authorship criteria) but are not listed as authors [14]. Other forms of unacceptable authorship are honorary or guest authorship (authorship is granted out of respect) and gift authorship (offered from a sense of obligation to a person who has not contributed to the work).

Oberlander and Spencer [15] discuss how students are a special group within research community when it comes to authorship. They are in relationships with their mentors where there is a possibility of exploitation [16], because of students' inexperience and their lack of knowledge. Oberlander and Spencer think that the best solution to discourage inappropriate authorship is education of students (as possible future scientist). They also give some recommendations for students as coauthors and for their mentors. Some of them are:

1. authorship guidelines from professional organizations and journals should be consulted

2. authorship should be discussed in an early phase of the research/work.

3. roles should be clarified

4. authorship should be based on relative contribution

5. acknowledgment section should be used appropriately

6. mentors should give some time to students to be innovative [15].

Committee on Publication Ethics (COPE) gives some advice about inappropriate authorship on students' papers [17]. They give examples of some anonymized cases (e.g. editor of a journal gives an example of a submitted manuscript that is work of students, but supervisor is listed as the first author).

One of the author's moral rights is the right to be stated as an author of his/hers work. Moral rights are part of author's rights, and author's rights are basic human rights, as stated in Universal Declaration on Human rights: "Everyone has the right to the protection of the moral and material interests resulting from any scientific, literary or artistic production of which he is the author" (article 27) [18]. Besides, violating moral rights is against the law: "Author has the right to be acknowledged and specified as the author of his/her work... author has the right to oppose to the use of his/hers work that is against his/hers reputation..." (Articles 15 and 16 of Croatian Copyright Act) [19].

\section{RESEARCH}

\section{A. Aim and scope}

The purpose of the research was to find out about the degree of knowledge about plagiarism and authorship issues among the Library and Information Science (LIS) students. The hypothesis were:

$\mathrm{H} 1$ : Students know that plagiarism is unethical behaviour, but are not sure what exactly plagiarism is.

$\mathrm{H} 2$ : There are students that commit plagiarism, but they are a minority.

H3: Students are not sure about the authorship criteria they sometimes think that any involvement in the research and/or paper is enough for a person to be listed as an author.

H4: Students learn about ethical issues on higher education level.

The results were supposed to be a starting point for deeper study (on national and international level) that should involve students from other departments, from other faculties and universities. The findings should be the basis for planning education on plagiarism and authorship.

\section{B. Methods}

An anonymous online questionnaire was sent to 75 graduate students of Library and Information Science at the Department of Information and Communication Sciences, Faculty of Humanities and Social Sciences, University of Zagreb. The questionnaire was sent in December 2016. Response rate was $76 \%$ - there was 57 responses.

There were 20 questions in the questionnaire. The first two questions were about gender and year of study $\left(1^{\text {st }}\right.$ or $2^{\text {nd }}$ graduate year). Another 18 questions were: multiply choice questions (6); one-choice questions (3) and yes/no questions (9).

\section{FINDINGS}

Question 1. Gender

There were 52 female and 5 male students in the sample. The percentage of male students is too small to make gender-related conclusions.

Question 2. Year of graduate study

In the sample are $36(63 \%) 1^{\text {st }}$ year students and $21(37 \%)$ $2^{\text {nd }}$ year students. 
Question 3. Have you learned about plagiarism at any degree of your education?

The question was multiple-choice type and the answers were: in elementary school; in secondary school; during undergraduate study; during graduate study; in some other informal form of education; no, never. Majority of the students have learned about plagiarism at undergraduate level, but seven students have never learned about plagiarism (Figure 1).

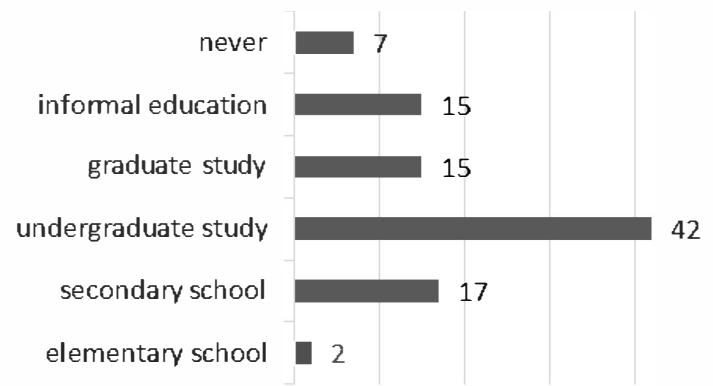

Figure 1. Degree of education when students learned about plagiarism

Question 4. If yes, what did you learn?

The question was multiple-choice type and the answers were: definition of plagiarism; ways of avoiding plagiarism; plagiarism detection; procedures in cases of detected plagiarism; definitions of authorship; authorship types; something else. Forty students (70\%) have learnt about the definition of plagiarism, $36(63 \%)$ have learnt about the definition of authorship, 28 (49\%) have learnt about authorship types, 26 (46\%) have learnt about avoiding plagiarism, 19 (33\%) have learnt about plagiarism detection and $9(16 \%)$ about procedures in cases of detected plagiarism. Three students (5.3\%) have learnt about all the topics.

Question 5. Have you ever presented other people's words, thoughts or ideas as your own, while preparing an assignment?

Eleven answers (19\%) were affirmative and 46 (81\%) were negative.

Question 6. Do you consider presentation of other people's words, thoughts or ideas as your own, ethically correct?

Forty-seven students (82\%) answered negative, and the other $10(18 \%)$ answered that it depended on the situation.

Question 7. Have you ever, before preparing an assignment, been taught about proper citing practice?

Twelve students (21\%) have never been taught about proper citing of sources, 22 (38\%) have been partly taught, and $23(41 \%)$ have been taught at least once about proper citing.

Question 8. Have you ever, before preparing an assignment, been taught how to make quotations?
Forty-nine answers (86\%) were affirmative and eight (14\%) were negative.

Question 9. Has any of your assignments ever been rejected because of wrong citation and/or quotation practice?

Nine answers (16\%) were affirmative and 48 (84\%) were negative.

Question 10. Have you ever been reported to an ethics committee for plagiarism?

There are no students in the sample that have been reported to an ethics committee for plagiarism.

Question 11. Have you ever been listed as author on a paper that you have not authored?

There were four affirmative answers (7\%) and 53 negative answers (93\%).

Question 12. Have you ever been omitted from the list of authors on a paper that you authored?

There were three affirmative answers (5\%) and 54 negative answers (95\%).

Question 13. Do you know about the case of wrong authorship assignment among your colleagues?

There were 21 affirmative answers (37\%) and 36 negative answers $(63 \%)$.

Question 14. Do you know about the case of plagiarism among your colleagues?

There were 24 affirmative answers (42\%) and 33 negative answers $(58 \%)$.

Question 15. Have you ever addressed an ethical committee or similar body to notify it about suspected plagiarism?

All the answers to the question were negative.

Question 16. Do you believe that self-plagiarism is possible?

8 students (14\%) think that self-plagiarism is impossible, 18 students $(32 \%)$ thing that it is possible, and 31 students (54\%) is not sure if self-plagiarism is possible.

Question 17. Indicate what plagiarism means to you.

The question was multiple-choice type and the answers were: quoting without citing sources; quoting with proper citation of sources; paraphrasing without citing sources; not implementing the rules of proper citing; compilation of texts with proper citation of sources; not assigning authorship to someone who authored the paper; something else. Fifty-six students (98\%) say that plagiarism is quotation without citing sources; 42 students $(74 \%)$ say that plagiarism is paraphrasing without proper citation of the sources; 41 students $(72 \%)$ think that plagiarism is when authorship is not properly assigned; 41 think (72\%) that plagiarism is when the rules of proper citing are not implemented; one student $(2 \%)$ thinks that quoting is plagiarism even if proper citing is 
applied and one (2\%) thinks that compiling texts is plagiarism even if proper citing is applied. Results are in Figure 2.

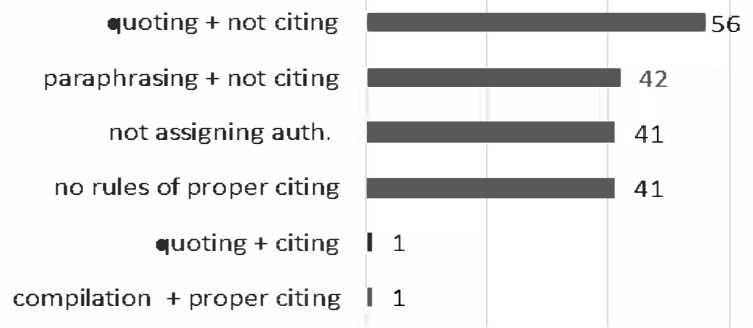

Figure 2. What is plagiarism?

Question 18. Mark all the criteria that are, in your opinion, criteria for authorship?

The question was multiple-choice type and the answers were: contribution to the concept of the work; writing the first version; financing of the research; collecting data; statistical analysis; giving final approval; technical support; something else.

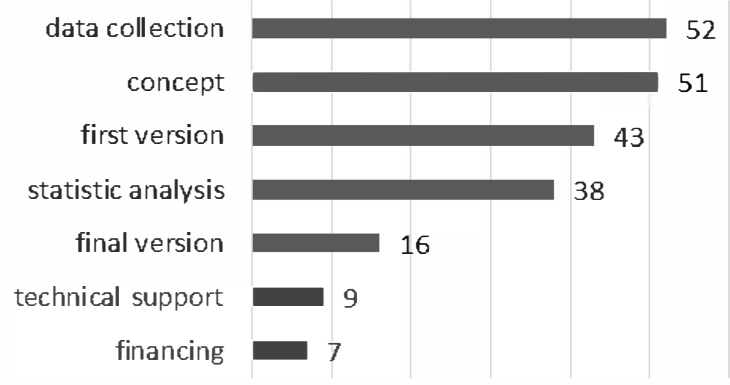

Figure 3. Authorship criteria

Fifty-two students (91\%) think that collecting data is authorship criteria; 51 (89\%) think that contribution to the research is authorship criteria; 43 (75\%) think that writing the first version is authorship criteria; 38 (67\%) think that doing statistical analysis is authorship criteria; $16(28 \%)$ think that approving final version is authorship criteria; 9 think that giving technical support is authorship criteria and $7(16 \%)$ think that financing is authorship criteria. Results are in Figure 3.

Question 19. Mark the applications you have heard about: Plagiarisma.net; iThenticate; Text Compare; Copy Leaks; Plagiarism Checker; MyText; Google Checker; nothing. Thirty-nine students (68\%) have not heard about any of the plagiarism detection software; 12 students $(21 \%)$ have heard of GoogleChecker (the software does not exist!); 7 (12\%) have heard of PlagiarismChecker; 6 (11\%) have heard of Copy Leaks; 3 (5\%) have heard of MyText (the software does not exist!); 2 (4\%) have heard of Plagiarisma.net and one ( $2 \%$ ) has heard of iThenticate.
Question 20. Mark the applications you have used: Plagiarisma.net; iThenticate; Text Compare; Copy Leaks; Plagiarism Checker; MyText; Google Checker; nothing. Fifty students (88\%) have never used any of the applications; four (7\%) have heard of PlagiarismChecker; three $(5 \%)$ have heard of GoogleChecker (the software does not exist!); two (4\%) have heard of Plagiarisma.net and one (2\%) has heard of MyText (the software does not exist!).

\section{DISCUSSION AND CONCLUSION}

Students mostly do learn about plagiarism during higher education. Only two students have learned about it in elementary school. That is the basic problem - children should be taught about ethics and plagiarism in elementary school, as it is showed in the Bailey's research [1]. Lack of early education about ethical issues seems to be problem in the later stages of education. When they learn about plagiarism, they are mostly taught about basic definition (of plagiarism and authorship) but not enough about detecting plagiarism and about procedures in the cases of suspected or detected plagiarism.

The lack of education is the most probable reason why:

- $19 \%$ of students have at least once presented other people's words, thoughts or ideas as their own, while preparing an assignment;

- 8\% of students think that sometimes (depending on situation) presenting other people's words, thoughts or ideas as their own can be ethically correct;

- $16 \%$ of students have at least once experienced rejection of their assignments because of wrong citation and/or quotation practice;

- $42 \%$ of students know at least about one case of plagiarism among their colleagues, but have never declared plagiarism;

- 37\% know about at least one case of wrong authorship assignment among their colleagues, but have never declared it;

- 5\% have at least once been omitted from the list of authors on papers that you authored, but have never declared it;

- 7\% have at least once been listed as authors on papers they have not authored, but have never declared it;

- $86 \%$ do not know what self-plagiarism is;

- 93\% do not use plagiarism detection software.

The limitation of the survey is that definition of plagiarism and/or authorship can be differently interpreted, since $30 \%$ of the students have never learnt about academic misconduct. However, $70 \%$ of the students claim that they have learned about the definition of plagiarism and high percentage of students can detect different forms of plagiarism (quoting without proper citation, paraphrasing without proper citation etc.). Sixtythree percent of the students state that they have learnt about the definition of authorship, but in fact, they are not sure what the authorship criteria are (e.g. 91\% think that collecting data is important for assigning authorship and 
$67 \%$ think that doing statistical analysis is important for authorship).

Another possible limitation of the survey is the use of self-report methodology. It is the most commonly used methodology in similar surveys [20] - students are mostly asked to answer anonymous questionnaires and to express their attitudes and experiences. Therefore, biased opinions are possible.

Despite small sample of the survey, results can be compared to some other studies. In 2011 Schrisher et al. [21] published results of a plagiarism survey from one US university. They concluded that academic misconduct is on the rise for many reasons, and the most important reason is that students think information on the Internet is public knowledge that is no one's intellectual property. However, most of them understand it is unacceptable to submit a paper written by someone else.

In Fish and Hura [22] 2013 survey, percentage of students that have used another author's phrases or ideas without citing the source is higher $(60 \%$ of students have at least once done that) than in our survey (about $20 \%$ of students). Fish and Hura found that college students consider some types of plagiarism as more serious than other types. Frequency of plagiarism is overestimated by students and therefore students are more likely to plagiarise. It is important for students to have accurate information about the frequency of plagiarism in their classes and institutions because such information could reduce the number of plagiarism incidents.

A study made by RefME service in 2016 [23] among almost 5000 US students shows that more than $50 \%$ of students have lost points for incorrect references (e.g. using the wrong style or not submitting full reference list). The survey has similar result to our survey where students were asked about lack of information on referencing (14\% of Croatian and about $20 \%$ of American students report lack of the information). There is a difference in the students' usage of plagiarism detection software $-88 \%$ of Croatian students do not use it while $54 \%$ of the US students do not use the software.

Bretag [20] describes various surveys noting that the rate of plagiarism among the students vary widely (from $18 \%$ to $81 \%$ ). International students and students for whom English is not their native language are more likely to commit plagiarism.

Important conclusion of our survey is that ethical issues are not part of education curricula. That is the reason of low awareness about ethical issues, namely plagiarism. Students should learn about authorship criteria and they should use plagiarism detection software more often. This survey was focused on unintended plagiarism, i.e. cases when students plagiarise without knowing they are doing something unethical or even illegal. Unintended plagiarism is undoubtedly result of lack of education.

The situation is similar in some other countries. Bretag [20] shows that $20 \%$ of postgraduate Australian students have never heard of academic integrity and $40 \%$ do not know whether their university has an academic integrity policy. As Adam et al. [24] assert - it is difficult to define plagiarism and there are no many researches that show the differences between institutional and student understanding of plagiarism.

Future researches of plagiarism in higher education should concentrate on:

- students' understanding of plagiarism;

- finding out how, where and when students learn about academic misconduct;

- finding out which teaching methods and techniques are (and should be) used for teaching about plagiarism

- analysing ethics policy documents in academic institutions;

- investigating and analysing higher education curricula

- finding out what tutors/teachers/professors know about plagiarism and what they do (or do not do) to avoid it in their work.

As mentioned earlier, the most commonly used methodology is self-report methodology (mostly questionnaires [22] and interviews [24]). Other methods should also be used, e.g. content analysis ([24] and [25]) where university policy documents are analysed; or experiments [26] that could help to investigate students' practices.

This research has a small sample and several upper mentioned limitations, but it can be used as a pilot study of students' plagiarism awareness in Croatia. New researches should be done with different samples among students of other studies at the Faculty but also among students of other faculties and universities in Croatia. Comparative analysis should be conducted and it should be a basis for some changes in educational curricula.

In conclusion, ethics literacy is one important part of information literacy - it is not enough to know how to find and evaluate information without knowing how to use it in a proper way, i.e. without violating anyone's basic rights. Therefore, action should be undertaken by educators, policy makers and funders of higher education institutions in order to raise knowledge and awareness of unethical nature of plagiarism and to deploy students' skills of avoiding plagiarism.

\section{REFERENCES}

[1] K. Olson, and A. Shaw, "No fair, copycat!': what children's response to plagiarism tells us about their understanding of ideas," Developmental Science, vol. 14, pp. 431-439, March 2010, doi: 10.1111/j.1467-7687.2010.00993.x

[2] J. Bailey, "What age do children see plagiarism as wrong?" Plagiarism Today. September 23, 2010. Retrieved December 27, 2016 from https://www.plagiarismtoday.com/2010/09/23/whatage-to-children-see-plagiarism-as-wrong/

[3] D. L. McCabe, "Cheating among college and university students: a North American perspective," International Journal of Educational Integrity, vol. 1, pp. 1-11, 2005. Retrieved December 27, 2016 from http://www.ojs.unisa.edu.au/index.php/IJEI/article/view/14

[4] A. Risquez, M. O'Dwyer, and A. Ledwith, "'Thou shals not plagiarize': from self-reoprted views to recognition andavoidance of plagiarism," Assessment and Evaluation in Higher Education, vol. 38, pp. 34-43, 2013

[5] L. Armstrong and R. Delbridge, "Final year undergraduate student plagiarism: academic staff and student perceptions," Learning and Teaching in Action, vol. 7, 2008 
[6] R. W. Dornan, L. M. Rosen, and M. Wilson, "Within and beyond the writing process in the secondary English classroom," Pearson Allyn \& Bacon, 2003.

[7] Middle Georgia State University, "Plagiarism prevention guide: why students plagiarise?," Retrieved December 27, 2016 from http://www.mga.edu/student-success-center/plagiarism/why.aspx

[8] The University of Melbourne, "Why and how students plagiarise?," Retrieved December 27, 2016 from https://academichonesty.unimelb.edu.au/turnitin/students/whyhow

[9] N. Kokemuller, "How plagiarism affects students," Seattle.pi. Retrieved December 27, 2016 from http://education.seattlepi.com/plagiarism-affects-students1023.html

[10] iThenticate, "6 consequences of plagiarism," Retrieved December 27, 2016 from http://www.ithenticate.com/resources/6consequences-of-plagiarism

[11] ICMJE, "Defining the role of authors and contributors," Retrieved December 27, 2016 from http://www.icmje.org/recommendations/browse/roles-andresponsibilities/defining-the-role-of-authors-and-contributors.html

[12] APA Science Student Council, “ A graduate student's guide to determining authorship credit and authorship order," 2006. Retrieved December 27, 2016 from http://www.apa.org/science/leadership/students/authorshippaper.pdf

[13] E. Wager, "Authors, ghosts, damned lies, and statisticians," PLoS Medicine, vol. 4, e34, 2007, doi: 10.1371/journal.pmed.0040034

[14] Washington University in St. Louis, "Washington University policy for authorship on scientific and scholarly publications," $\begin{array}{llll}\text { Retrieved December 27, } 2016 \text { from } & \text { 27 }\end{array}$ http://research.wustl.edu/PoliciesGuidelines/Pages/AuthorshipPoli cy.aspx

[15] S. E. Oberlander and R. J. Spencer, "Graduate students and culture of athorship," Ethics and Behaviour, vol. 16, pp. 217-237, 2006, Retrieved December 27, 2016 from http://155.97.32.9/ bbenham/Phil\%207570\%20Website/pdfsAuthorship/Oberlander-Spencer-2006EB_GraduateAuthorship.pdf

[16] M. M. Costa M. Gatz, "Determination of authorship credit in published dissertations," Psychological Science, vol. 3, pp. 354357, 1995.

[17] COPE, "Inappropriate authorship on students paper," Retrieved December http://publicationethics.org/case/inappropriate-authorshipstudents-paper

[18] UN, "Universal declaration on human rights", Retrieved $\begin{array}{lccc}\text { December } & 27 & 2016 & \text { from }\end{array}$ http://www.ohchr.org/EN/UDHR/Documents/UDHR_Translations /eng.pdf

[19] "Croatian Copyright act", Narodne novine, no. 167, 2003

[20] Bretag, T. "Challenges in addressing plagiarism in education," PLOS Medicine, 20, 2013, doi: 10.1371/journal.pmed.1001574

[21] R. H. Schrimsher, L. A. Northrup, and S. P. Alverson, "A survey of Samford University students regarding plagiarism and academic misconduct," International Journal for Educational Integrity,vol. 7, pp. 3-17, 2011. Retrieved February 22, 2017 from http://www.ojs.unisa.edu.au/index.php/IJEI/article/view/740

[22] R. Fish, and G. Hura. "Students' perceptionsof plagiarism," Journal of the Scholarship of Teaching and Learning, vol. 13. Pp. $33-45$, 2013. Retrieved February 22, 2017 from: http://josotl.indiana.edu/article/download/4254/3862

[23] RefME. "10 things we discovered about students' attitudes towards plagiarism," July 25, 2016. Retrieved February 22, 2017 from: https://www.refme.com/blog/2016/07/25/10-thingsdiscovered-students-attitudes-towards-plagiarism/

[24] L. Adam, V. Anderson and R. Spronken-Smith, "It's not fair": policy discourses and students' understandings of plagiarism in a New Zealand university," Higher Education, vol. 72, pp. 1-16, 2016. doi: 10.1007/s10734-016-0025-9

[25] I. Hebrang Grgić, "IL and information ethics: how to avoid plagiarism in scientific papers?" in Information literacy: lifelong learning and digital citizenship in the $21^{\text {st }}$ century: second European Conference ECIL: proceedings, pp. 217-226 Heidelberg: Springer, 2014

[26] T. S. Dee and B. A. Jacob, "Rational ignorance in education: a field experiment in student plagiarism," National Bureau of Economic Resaerch Working Paper Series, 2010, Retrieved March 6, 2017 from http://www.nber.org/papers/w15672.pdf 